\title{
O estado da arte dos determinantes do voto no Brasil e as lacunas existentes
}

\author{
Adriano Oliveira \\ Doutor em Ciência Política (Universidade Federal de Pernambuco) \\ Professor na Universidade Federal de Pernambuco \\ adrianopolitica@uol.com.br
}

\begin{abstract}
Resumo Por meio da revisão dos determinantes do voto apresentados pela literatura brasileira e da apresentação das premissas básicas do neoinstitucionalismo, este artigo tem o objetivo de mostrar as contribuições dos variados autores no que condiz às explicações das escolhas do eleitor; evidenciar as lacunas de pesquisas existentes no âmbito das obras que abordam os determinantes do voto; justificar a necessidade da utilização do neoinstitucionalismo na interpretação do comportamento do eleitor. Conclui-se que, para a robusta compreensão teórica e empírica da escolha do eleitor, é necessária a utilização do neoinstitucionalismo na interpretação da influência dos determinantes do voto.
\end{abstract}

Palavras-chave: comportamento eleitoral, determinantes do voto, eleições, escolha, neoinstitucionalismo.

\section{Introdução}

A literatura brasileira sobre estudos eleitorais é extensa. Variadas obras oferecem ao leitor muitas descrições sobre as eleições ou procuram explicar o comportamento do eleitor - na maioria, encontram-se obras empíricas. Entretanto, existem trabalhos tipicamente teóricos que procuram explicar as escolhas do eleitor e merecem ser destacados. ${ }^{1}$

Descrever as eleições representa a narrativa do processo eleitoral, ou seja, é o relato do modo como o eleitor votou e em que segmentos socioeconômicos, ideológicos ou religiosos um candidato obteve mais votos, por exemplo. Na narrativa de um fenômeno, abstém-se de analisá-lo e de revelar as possíveis relações de causalidade que lhe dão vida (Van Evera, 1997; Popper, 2004; Taleb, 2009).

Decifrar dado fenômeno eleitoral significa evidenciar as causas que motivam o indivíduo ou o conjunto deles a tomar determinada decisão. Ao decifrar o comportamento do eleitor, fenômenos sociais, especificamente os eleitorais, são elucidados (Boudon, 1995; Elster, 2006).

Por exemplo: o fenômeno eleitoral X existe em razão da influência da variável A. Esta, por sua vez, só existe em razão de Z, a qual se manifesta diante das condições Y. Assim, estamos diante de relações de causalidade (Van Evera, 1997) ou dos mecanismos entre as variáveis que dão vida a determinado fenômeno (Elster, 1997). Os fenômenos 
eleitorais se explicam dessa forma. Portanto, decifrar é identificar os determinantes e as causas que dão vida aos fenômenos.

Figueiredo (1991) apresenta um pioneiro e importante trabalho teórico sobre o comportamento do eleitor, em que ele estrutura teoricamente a compreensão dos determinantes do voto apresentados pela literatura empírica brasileira. Para Figueiredo (1991), os eleitores fazem escolhas racionais. Nesse caso, a racionalidade do eleitor é uma premissa teórica que fornece condição, e a torna inteligível, à influência de alguns dos variados determinantes do voto sugeridos pelos estudos empíricos. ${ }^{2}$

No âmbito das obras empíricas sobre comportamento eleitoral, destacam-se os trabalhos que procuram explicar as razões da escolha do eleitor em disputas majoritárias por meio das clivagens ideológicas e do lulismo (Singer, 2000; 2009; Oliveira, 2011); da preferência partidária (Carreirão; Barbetta, 2004); da imagem dos candidatos (Carreirão, 2002a); da emoção (Pimentel Júnior, 2007; 2010; Lavareda, 2011); da aprovação à administração e do bem-estar econômico (Almeida, 2008; Carreirão, 2009; Peixoto; Rennó, 2011); da cultura política (Lourenço, 2007); do impacto do guia eleitoral (Veiga, 2001); e da influência das estratégias de campanha (Lavareda, 2009; Telles, 2009). ${ }^{3}$

Verifica-se, contudo, que a literatura brasileira que aborda especificamente os determinantes do voto, apesar das variadas e meritórias tentativas, não explica de modo satisfatório as razões que motivam o eleitor a realizar dadas escolhas. As diversas obras aqui analisadas respondem a vários problemas, mas sugerem outros, os quais continuam sem resposta.

Este artigo tem os seguintes objetivos: 1) mostrar a contribuição dos variados autores no que condiz à explicação das escolhas do eleitor; 2) evidenciar as lacunas de pesquisas existentes no âmbito das obras que abordam os determinantes do voto; 3) mostrar a necessidade da utilização do neoinstitucionalismo na interpretação do comportamento do eleitor. ${ }^{4}$

Para a contemplação dos objetivos sugeridos, revisamos diversos atores que abordam as eleições no
Brasil a partir da década de $1990 .{ }^{5} \mathrm{Nem}$ todas as obras serão objeto de análise, pois na escolha consideramos os determinantes do voto que cada uma delas aborda. Desse modo, excluímos vários trabalhos por abordarem determinantes semelhantes.

Inicialmente, analisamos a pioneira obra teórica de Figueiredo (1991). Procuramos evidenciar as lacunas do seu trabalho no âmbito da explicação teórica da escolha do eleitor. Em seguida, por meio da revisão das obras empíricas que abordam os determinantes do voto, mostramos problemas ainda não respondidos por elas. Em algum momento, apresentamos dados empíricos para fortalecer, enfraquecer ou esclarecer as teses dos atores abordados.

Noutra seção, expusemos a convergência entre as lacunas teóricas e empíricas apresentadas, procurando justificar a introdução do neoinstitucionalismo para responder aos problemas oferecidos no decorrer do texto. Conclui-se com a sugestão de que o neoinstitucionalismo seja incorporado à análise das escolhas eleitorais.

\section{A lacuna teórica}

Por que os indivíduos votam em certo candidato? Figueiredo (1991) procura responder teoricamente a essa indagação. A obra de Figueiredo arrisca construir uma teoria explicativa do comportamento do eleitor. Ao apresentar diversas escolas teóricas, apesar da inexistência de indicadores empíricos, o autor contribui para que o comportamento do eleitor brasileiro seja decifrado. ${ }^{6}$

Figueiredo (1991), sem intenção, insere a discussão dos motivos da ação social nos estudos sobre o comportamento do eleitor brasileiro. O primeiro princípio da sociologia da ação social é que todo fenômeno social, qualquer que seja, "é sempre o resultado de ações, de atitudes, de convicções, e em geral de comportamentos individuais" (Boudon, 1995, p. 28). Nesse sentido, para explicar fenômenos sociais, é necessário "procurar o sentido dos comportamentos

2. Em 2008, a obra de Figueiredo (1991) foi republicada pela Editora da UFMG.

3. Este artigo aborda, exclusivamente, os determinantes do voto em disputas majoritárias, em particular, na competição eleitoral entre candidatos aos cargos de prefeito, governador e presidente da República.

4. O neoinstitucionalismo é uma linha teórica contemporânea da Ciência Política que tem o objetivo de explicar o comportamento dos indivíduos e das instituições. O neoinstitucionalismo divide-se em três vertentes principais: o institucionalismo histórico, o sociológico e o da escolha racional. Essas três escolas interagem, uma vez que elementos de um complementam o outro no desenvolvimento de análises institucionais ou do comportamento dos indivíduos (cf. Hall; Taylor, 2003; Peters, 2003; Aoki, 2007; Rezende, 2009; 2012).

5. Desde 1989, as eleições para a Presidência da República do Brasil ocorrem continuamente, o que contribuiu para que mais estudos eleitorais e pesquisas de opinião florescessem, as quais sugeriram variados determinantes do voto.

6. A obra de Figueiredo (1991) é teórica, em razão disso, até hoje, seu pioneirismo e ineditismo. Ela foi publicada após a primeira eleição direta para presidente da República depois do fim da ditadura militar. Já ocorreram seis eleições diretas presidenciais. Em virtude das variadas eleições, diversos trabalhos empíricos sobre o comportamento do eleitor surgiram. Muitos desses trabalhos estruturam teoricamente seus argumentos com base em Figueiredo (1991). 
individuais que estão em sua origem” (Boudon, 1995, p. 28). ${ }^{7}$

Os argumentos de Boudon (1995) permitem que se reconheça que o desempenho dos candidatos em uma eleição é um fenômeno social, assim como o comportamento dos eleitores. São as escolhas do eleitor que constroem o desempenho do candidato no processo eleitoral. Portanto, o que motiva o eleitor a escolher certo candidato? Ou melhor: o que motiva a ação social do eleitor?

As respostas a essas indagações encontram respaldo teórico em três escolas teóricas apontadas por Figueiredo (1991), quais sejam: a sociológica, a de Michigan e a escolha racional. Para a escola sociológica, o comportamento político é função da natureza e da densidade "das interações em que os indivíduos estão envolvidos, das opiniões que formam a partir daí e do estado socioeconômico da sociedade na qual ocorre esse comportamento" (Figueiredo, 1991, p. 49).

O modelo de Michigan utiliza-se da psicologia para explicar o comportamento do eleitor. Para esse modelo, as atitudes políticas se formam e se integram na sociedade. Os indivíduos, ao conviverem socialmente, adquirem atitudes que estruturam sua personalidade. Para o modelo de Michigan, o comportamento político é função do ambiente social (Figueiredo, 1991, p. 20-21). O modelo de Michigan é semelhante ao sociológico. Ambos consideram que as interações sociais possibilitam, condicionam as escolhas.

A teoria da escolha racional (TER) explica o comportamento do eleitor considerando os custos e os benefícios individuais. $\mathrm{O}$ ato de votar tem uma função estratégica e instrumental. O eleitor está diante de várias opções. A escolha do eleitor é orientada pela expectativa de conquista ou manutenção de benefícios (Figueiredo, 1991; Downs, 1999).

$\mathrm{O}$ ator racional vê o voto como duas escolhas: manter seu bem-estar ou não. A base que os eleitores usam para avaliar o desempenho dos governantes é sua situação social. "O critério de decisão do eleitor está no grau de satisfação que ele obtém do desempenho dos governantes" (Figueiredo, 1991, p. 77).

Boudon (1995, p. 34) salienta que o indivíduo não está num "vazio social”. Ele interage com outros indivíduos, e essa interação condiciona a ação social do indivíduo. No caso, os indivíduos interagem valores, e estes condicionam a escolha racional ou não do indivíduo. Os valores, adquiridos ou construídos em razão das interações sociais, condicionam sua preferência (Hall; Taylor, 2003).

Para Reis (2000, p. 159), a "racionalidade é necessariamente 'contextual' e a ideia de uma racionalidade política invariante é contraditória nos próprios termos". A argumentação de Reis sugere que a compreensão da decisão do ator requer o entendimento do contexto e neste, conforme frisa Boudon (1995), estão presentes interações sociais. ${ }^{8}$

A ideia de "vazio social" proposta por Boudon (1995) é corroborada por Przeworski (2005), Aoki (2007) e Rezende (2009). Para esses autores, a compreensão da ação social do indivíduo requer duas premissas básicas: 1) os indivíduos agem dentro de um contexto, em que atuam variáveis diversas que condicionam ou incentivam a ação do ator; 2) os indivíduos interagem socialmente em vários instantes (estágios sociais) de sua trajetória e, por consequência, formam suas preferências.

As duas premissas apresentadas se complementam. O indivíduo ao agir sofre influência do contexto em que está incluso. Por sua vez, a escolha do indivíduo, assim como o contexto, é construída a partir do percurso numa dada trajetória. O contexto influencia o indivíduo e este pode vir a criar o contexto/ambiente social. Na trajetória existem estágios. Em cada um, o indivíduo pode formar ou mudar sua preferência de escolhas, já que causas diversas atuam na formação da sua tomada de decisão (Przeworski, 2005, p. 70).

As premissas mostradas fazem parte do neoinstitucionalismo, especificamente da interação dos institucionalismos histórico, sociológico e da escolha racional. Para essas escolas teóricas, os indivíduos formam suas preferências numa trajetória - institucionalismo histórico. Eles sofrem influências diversas em virtude das interações sociais que ocorrem na trajetória e das instituições, as quais devem ser reconhecidas como organizações formais, valores e modelos mentais - institucionalismo sociológico (Peters, 2003, p. 159).

A escolha do indivíduo, portanto, não é vazia; ela deve ser endógena e dinamicamente compreendida, já que as escolhas dos indivíduos se formam na trajetória social e nesta ocorrem interações sociais (troca de valores, formação de crenças e modelos mentais) e a influência das instituições formais, por exemplo, regras eleitorais. Interações sociais e instituições formais e informais influenciam ou condicionam a ação

7. "Para explicar um fenômeno social, é necessário descobrir as causas individuais, ou seja, compreender as razões que levam os atores sociais a fazer o que fazem ou a acreditarem naquilo em que acreditam” (Boudon, 1995, p. 28).

8. "[...] a racionalidade é necessariamente 'contextual', e a ideia de uma racionalidade política invariante é contraditória nos próprios termos. Isso não nega, naturalmente, o que pode haver de interesse em revelar que certa literatura dedicada aos partidos políticos brasileiros no período estudado tende a ignorar a complexidade e a variedade das condições ou dos ambientes concretos em que os partidos políticos tinham de atuar se tem em mente o contraste entre os níveis federal e regional, bem como a diversidade de condições regionais” (Reis, 2000, p. 159). Carpenter (2009, p. 67) corrobora Reis, ao afirmar que os valores importam para as escolhas dos indivíduos. 
social do indivíduo (Hall; Taylor, 2003; Przeworski, 2005; Aoki, 2007; Rezende, 2009). ${ }^{9}$

A ação social do indivíduo pode ser racional. No caso, ele age estrategicamente com o objetivo de manter benefícios. No entanto, a tipificação da sua ação como racional está a depender do contexto social, pois este orienta seu ato. No contexto encontram-se a cultura (valores, crenças, modelos mentais) e instituições formais (regras, por exemplo) que interferem nas escolhas dos indivíduos, porque sugerem o que é apropriado fazer (Hall; Taylor, 2003, p. 221).

As premissas teóricas do neoinstitucionalismo se formam por pressupostos advindos das escolas sociológica, de Michigan e da escolha racional, as quais foram apresentadas por Figueiredo (1991). Salientamos, contudo, que esse autor não interage com ou provoca o diálogo entre as três escolas apresentadas com o objetivo de explicar teoricamente a escolha do eleitor. Ele aborda as escolas de modo separado, sugerindo que elas não se complementam ou interagem quando da explicação da escolha dos indivíduos.

Figueiredo (1991, p. 204) conclui sua obra com a afirmação de que "o eleitor dispõe-se a participar e dar seu voto a alguém quando e se o jogo eleitoral o faz compreender que o seu voto é decisivo, isto é, é o voto que maximiza a utilidade esperada da ação". Essa argumentação se estrutura preponderantemente por pressupostos típicos da teoria da escolha racional.

Considerando o neoinstitucionalismo, existe a hipótese de que os eleitores formam suas preferências eleitorais numa trajetória, e nela eles adquirem ou formam valores, crenças e modelos mentais. Além disso, podem sofrer influência das instituições formais. Esses aspectos condicionam ou influenciam as escolhas dos eleitores, as quais podem ser racionais conforme o contexto social em que se encontram (Reis, 2000; Hall; Taylor, 2003; Aoki, 2007; Rezende, 2009).

A ausência do diálogo entre as três escolas apontadas por Figueiredo (1991, p. 201, 204) torna sua conclusão - a qual afirma que o eleitor age racional e estrategicamente - insuficiente para explicar o comportamento do eleitor, uma vez que sua obra não responde ao seguinte problema: de que maneira os eleitores formam sua preferência eleitoral racional?

Apesar de Figueiredo (1991) contribuir para a explicação sobre a escolha do eleitor, existe uma lacuna teórica em sua obra. O autor não aborda a formação da preferência eleitoral do eleitor numa trajetória em que ocorrem interações sociais, construção ou absorção de valores, a influência de instituições formais e informais, e, por consequência, uma possível escolha racional. ${ }^{10}$

\section{As lacunas empíricas}

As escolas teóricas apresentadas na obra de Figueiredo (1991) estruturam, quando abarcadas coletivamente, a compreensão dos variados trabalhos empíricos sobre o comportamento do eleitor apresentados a seguir. Esses trabalhos procuram mostrar empiricamente quais os determinantes que orientam a escolha eleitoral do indivíduo. Os determinantes do voto que serão apresentados buscam responder empiricamente à seguinte indagação: o que motiva o eleitor a escolher certo candidato?

\section{Ideologia, preferência partidária e Iulismo}

Singer (2000), analisando as eleições de 1989 e 2002, procura explicar o que motiva a escolha eleitoral dos indivíduos. Para o autor, parte dos eleitores faz sua escolha considerando o espectro ideológico em que se insere - esquerda, direita, centro etc. ${ }^{11}$ Assevera que existe o voto ideológico no Brasil, visto que diversos eleitores fazem suas escolhas considerando sua posição ideológica (Singer, 2000).

A identificação ideológica por parte do eleitor significa a adesão a uma posição no contínuo "esquerda-direita ou liberal-conservador que, mesmo sendo difusa, isto é, cognitivamente desestruturada, sinaliza uma orientação política geral do eleitor" (Singer, 2000, p. 49).

Carreirão (2002a; 2002b) discorda parcialmente de Singer (2000), quando diz que os eleitores têm dificuldades em apontar características/atributos aos espectros esquerda e direita; em particular, os com menor grau de escolaridade.

\footnotetext{
9. Regras sociais são exemplos de instituições informais.

10. Na conclusão deste artigo, apresentam-se mais argumentos quanto à contribuição do neoinstitucionalismo para explicar a formação da preferência do eleitor. Ressalte-se que, neste momento, pesquisamos sobre a importância da interdisciplinaridade na explicação do comportamento do eleitor. Ou seja, o diálogo entre fundamentos da neurociência, do neoinstitucionalismo e da antropologia das emoções pode contribuir para dar robustez teórica à explicação da formação da preferência eleitoral.

11. Compreende-se ideologia em dois sentidos, os quais não são excludentes. No primeiro sentido, ideologia é o "conjunto difuso de valores, crenças ou ideias de qualquer tipo que se associam a determinada configuração de condições sociais gerais (posição de classe, época, nacionalidade) e que vêm a constituir, em última análise, a visão de mundo das pessoas. O segundo sentido é o que a palavra adquire usualmente quando se trata de 'ideologia política': aqui se dá ênfase à noção de um conjunto estruturado e coerente de ideias, que encerra como dimensão saliente a de estar destinado a servir de guia de ação" (Reis, 2000, p. 281).
} 
O autor afirma que é exagerado o peso dado por Singer (2000) aos aspectos ideológicos na explicação dos motivos que orientam/determinam a escolha do eleitor, pois outras variáveis revelam "ter maior influência na determinação dos resultados das eleições presidenciais recentes" (Carreirão, 2002b, p. 75). ${ }^{12}$

Ao analisar o comportamento do eleitor na eleição presidencial de 2002 na Grande São Paulo, Carreirão (2004) mostra a importância de considerar a variável "preferência partidária" na explicação da escolha do eleitor.

Pesquisa do Instituto de Pesquisa Maurício de Nassau (IPMN), realizada em Pernambuco em maio de 2010, corrobora os argumentos de Carreirão (2004). ${ }^{13}$ A pesquisa revela que existe associação estatisticamente significativa entre intenção de voto e preferência partidária. ${ }^{14} \mathrm{Na}$ eleição presidencial de 2010, Dilma Rousseff tem 73\% de intenção de votos em Pernambuco entre os admiradores do seu partido - Partido dos Trabalhadores (PT) - 39,6\%.

Ressalte-se que o modelo de regressão logística, construído com base em survey do IPMN em Pernambuco (maio de 2010), revela que, dentre as variáveis "Avaliação da administração", "Bem-estar econômico" e "Preferência partidária", o efeito positivo desta última não é relevante, ao contrário das outras.

Após o primeiro mandato do presidente Lula (2006), na percepção dos eleitores, houve a diluição das diferenças ideológicas entre os partidos (Carreirão, 2007). Por consequência, ocorreu menor associação entre ideologia e escolha eleitoral na disputa presidencial de 2006.

Carreirão (2008) mostra, após considerar surveys no Brasil em diferentes anos (1990, 1997, 2002 e 2007), que as opiniões políticas dos eleitores que manifestam sentimentos por agremiações partidárias não são tão díspares no final do período analisado. Portanto, essa conclusão sugere que os eleitores não sabem diferenciar os partidos.

Limongi e Mesquita (2008) mostram explicação alternativa à de Carreirão (2008). De acordo com esses autores, entre 1985 e 2004, ocorreu um fortalecimento concomitante dos candidatos da direita e da esquerda. Mas foram os eleitores de centro que decidiram as eleições. A explicação dos autores reforça a tese de Singer (2000), qual seja: os eleitores fazem escolhas eleitorais com base na ideologia.

As obras de Singer (2000), Carreirão (2002a; 2002b; 2004; 2007; 2008) e Limongi e Mesquita (2008) sugerem o seguinte questionamento: o eleitor sabe atribuir características/atributos aos espectros ideológicos $e$, por consequência, às agremiações partidárias?

Singer (2009) abandona parcialmente a utilização dos espectros ideológicos tradicionais, no caso, esquerda e direita, e sugere uma nova categoria ideológica, qual seja, o lulismo. Essa nova categoria serve para explicar as escolhas do eleitor, embora o autor não reconheça isso.

Segundo Singer (2009), o lulismo é uma nova configuração ideológica que mistura elementos da esquerda e da direita. Com a intenção de justificar ou comprovar essa mistura, o autor afirma que os indivíduos adeptos do lulismo têm "a expectativa de um Estado o suficientemente forte para diminuir a desigualdade, mas sem ameaçar a ordem estabelecida" (Singer, 2009, p. 84).

Com base em Singer, definimos o lulismo como a união de indivíduos com preferências eleitorais semelhantes, as quais podem ser encontradas e correspondidas ou não nos diversos espectros ideológicos clássicos, esquerda, direita, centro etc. Nesse sentido, Luiz Inácio Lula da Silva, em seus dois mandatos presidenciais - 2002 a 2010 -, representou os interesses e o atendimento das demandas advindas de variados segmentos, independentemente das clivagens ideológicas. Em razão disso, surge o lulismo.

As demandas atendidas pelo governo Lula vieram de eleitores de diversos espectros ideológicos, inclusive daqueles indivíduos que afirmam não ter ideologia. O lulismo, portanto, é uma variável que motivou o enfraquecimento das ideologias clássicas. O lulismo possibilitou a divisão do eleitorado em dois possíveis segmentos específicos: os que apoiam e admiram a figura de Lula e os que fazem oposição a Lula. Enfim, o lulismo fortalece o personalismo na dinâmica eleitoral (Oliveira, 2011).

Em suas obras, Singer (2000; 2009) procura explicar a escolha do eleitor por meio das clivagens ideológicas existentes na sociedade brasileira. Ressaltamos que os argumentos oferecidos pelo autor, os quais se fundamentam em dados empíricos, são convincentes. Isso significa que, na tentativa de compreender a escolha do eleitor, é necessário considerar a posição ideológica dele além do lulismo.

Porém, de acordo com Borba (2005), não existe um sentimento ideológico entre os eleitores. São os atributos pessoais dos candidatos, como honestidade e competência, que orientam a escolha do eleitor. Esses atributos sugerem forte presença do personalismo na política brasileira (Borba, 2005, p. 164).

12. Em survey realizado em maio de 2010 em vários estados do Brasil, o Instituto Datafolha mostrou que $17 \%$ dos entrevistados se consideram de centro; veem-se mais próximos à esquerda 20\%; identificam-se mais com a direita $37 \%$ e $25 \%$ não sabem identificar seu espectro político. 13. Para Reis (2000, p. 282), "os temas da preferência partidária e do comportamento eleitoral articulam-se normalmente, na literatura de ciência política, com o tema da ideologia”.

14. Realizou-se teste estatístico de associação entre preferência partidária e escolha eleitoral. 0 teste apresentou p-valor <0,05, indicando uma relação estatisticamente significativa entre as referidas variáveis. 
Os argumentos de Borba (2005) enfraquecem as considerações de Singer (2000) sobre a escolha do eleitor, mas reforçam a importância de considerar o lulismo como determinante do voto.

Ressaltamos que Dilma Rousseff, candidata do PT e apoiada por Lula, venceu a eleição presidencial de 2010. No período eleitoral, $83 \%$ dos eleitores brasileiros consideravam o governo Lula bom/ótimo, conforme a pesquisa do Datafolha de 26 de outubro de 2010 , e, para $76 \%$, o presidente Lula era confiável - pesquisa do Ibope em 27 de setembro de 2010.

O sucesso eleitoral de Dilma e os dados referentes ao presidente Lula sugerem que se deve incluir o lulismo como uma das variáveis que influenciaram o sucesso eleitoral de Dilma Rousseff na eleição de 2010.

O lulismo deve ser compreendido como a convergência de interesses provenientes dos indivíduos com valores ideológicos ou não. Portanto, como já destacado, temos a hipótese de que o lulismo enfraquece os argumentos de Singer (2000), voto ideológico, e reforça a tese de Borba (2005), Singer (2009) e Oliveira (2011) - personalismo na política e lulismo.

\section{A imagem dos candidatos e as emoções}

Com base nas eleições presidenciais de 1989, 1994 e 1998, Carreirão (2002a) afirma que a imagem política, os atributos pessoais dos candidatos e o desempenho do governo em exercício, em particular na área econômica, são alguns fatores que constroem a escolha do eleitor.

Segundo Carreirão (2002a), os atributos dados aos candidatos pelos eleitores possibilitam a identificação de qual é a imagem que estes têm dos competidores. Segundo Carreirão, a orientação do voto do eleitor depende da imagem que ele tem dos candidatos. Existe, portanto, uma dimensão simbólica na relação competidor-eleitor (Carreirão, 2002a, p. 33).

Survey realizado pelo IPMN, em julho de 2010, procurou verificar qual era a imagem que os eleitores tinham do candidato à reeleição ao governo de Pernambuco Eduardo Campos - do Partido Socialista Brasileiro (PSB) - nas eleições de 2010. Qual é a imagem que você tem do governador Eduardo Campos?
Mediante essa indagação, foi possível diagnosticar os atributos que os eleitores reconheciam no candidato do PSB. A pesquisa revelou que $55,3 \%$ dos eleitores consideravam "boa/ótima" a imagem de Eduardo Campos e, para 3,3\%, ele era "trabalhador/lutador".

Segundo 41,9\% dos entrevistados, Jarbas Vasconcelos, do Partido do Movimento Democrático Brasileiro (PMDB), principal oponente do governador Eduardo Campos na disputa eleitoral de 2010, tinha uma imagem "boa/ótima", e 1,4\% o classificaram como trabalhador. ${ }^{15}$

Qual foi o melhor governador de Pernambuco nos últimos tempos? Essa pergunta do IPMN teve a intenção de verificar qual era a imagem que os eleitores tinham do governo dos principais competidores - Eduardo Campos e Jarbas Vasconcelos. Essa indagação possibilitou verificar a memória do eleitor em relação a eles.

A pesquisa revela que $35,3 \%$ dos entrevistados consideravam que Eduardo Campos foi o melhor governador de Pernambuco nos últimos tempos. ${ }^{16}$ Já 22,3\% apontavam Jarbas Vasconcelos.

Esses dados possibilitam a construção da seguinte hipótese: a memória do eleitor em relação ao gestor governamental depende da sua imagem construída durante seu mandato.

Na disputa presidencial de 2010, os dois principais competidores tiveram sua imagem avaliada por survey. Dilma Rousseff foi reconhecida por $42 \%$ dos eleitores como a candidatura mais preparada para a Presidência do Brasil. Para 38\%, Serra estava mais preparado do que Dilma - conforme divulgou a Pesquisa Datafolha de 25 de agosto de 2010. ${ }^{17}$

Como bem mostram os argumentos dos diversos autores e dados de surveys, a imagem do candidato pode ser considerada um determinante do voto. Porém, de que modo a imagem do candidato é construída, aceita ou rejeitada pelo eleitor? Que premissa teórica fundamenta a imagem como determinante do voto?

Pimentel Júnior $(2007$; 2010) disserta sobre o papel das emoções na escolha do eleitor. ${ }^{18} \mathrm{O}$ autor busca construir um diálogo entre razão, no caso, escolha racional e emoção. De acordo com ele, baseado no modelo de inteligência afetiva (Marcus, 2003), os eleitores têm entusiasmo e ansiedade. ${ }^{19}$

A hipótese de Pimentel Júnior (2010) é que eleitores entusiasmados estão predispostos a votar em deter-

15. Jarbas Vasconcelos foi governador de Pernambuco no período 1998-2006

16. O governador Eduardo Campos foi reeleito governador de Pernambuco no primeiro turno com $82,83 \%$ dos votos válidos.

17. Dilma Rousseff foi eleita presidente do Brasil no segundo turno com $56 \%$ dos votos válidos. Seu oponente, José Serra, obteve $44 \%$ dos votos válidos.

18. Na literatura internacional sobre emoções e escolha eleitoral, cf. Westen (2007).

19. O modelo de inteligência afetiva "advoga que as emoções possuem duas dimensões distintas: uma dimensão positiva, denominada entusiasmo, e outra negativa, chamada ansiedade. Tais emoções não possuem apenas uma função avaliativa, no sentido de que se o sentimento é negativo, as considerações cognitivas em relação ao objeto que engendra tal sentimento também serão, ou se positivo, que tenderemos a avaliá-lo melhor. A função das emoções dentro desse modelo é um pouco mais complexa: por um lado, regulam comportamentos rotineiros e, por outro, a atenção consciente" (Pimentel Júnior, 2010, p. 519). 
minado candidato. Eleitores ansiosos estão em dúvida quanto à sua escolha eleitoral. Para o autor, a ansiedade do eleitor representa a reflexão quanto às vantagens e desvantagens de escolher algum candidato.

De acordo com Pimentel Júnior (2010), eventos ocorridos durante a campanha eleitoral podem interferir na predisposição do eleitor em votar no candidato. Como ele bem mostra, por meio de análise quantitativa, o candidato bem avaliado pode vir a vencer a disputa no segundo turno em razão de que denúncias de corrupção criaram ansiedade nos eleitores e os levaram a repensar seu voto no primeiro turno.

Para o modelo de inteligência emocional, a avaliação dos governos, no caso, o voto retrospectivo, não é puramente racional. "Eleitores não precisam estar conscientes das realizações do governo para compreender que a situação do país é melhor ou pior e nem verbalizar as razões disso" (Pimentel Júnior, 2010, p. 528). Os eleitores podem avaliar o governo pela intuição afetiva. Ou seja: "Se a situação vai bem, sentimentos de entusiasmos são engendrados, enquanto que, se a situação vai mal, o sentimento de ansiedade aumenta" (Pimentel Júnior, 2010, p. 528).

Lavareda (2009; 2011) analisa o papel das emoções nas escolhas eleitorais dos indivíduos. De modo inovador, apresenta as diferenças entre emoção e sentimentos, revelando que a emoção surge antes dos sentimentos e ambos são construídos numa trajetória. $\mathrm{O}$ autor acrescenta que emoções e sentimentos estão associados à memória dos indivíduos e à imagem. Neste último caso, Lavareda (2011) revela empiricamente que a imagem de candidatos provoca reações emocionais nos eleitores. ${ }^{20}$

Imagem e emoções, determinantes do voto, relacionam-se entre si. A imagem do candidato X pode causar emoção nos eleitores. Com isso, os eleitores adquirem predisposição para votar nele. Então, indaga-se: em que contextos e como as emoções e os sentimentos dos eleitores em relação aos candidatos são construídos? A hipótese é que a convivência eleitor-candidato possibilita o surgimento de aspectos emotivos, como esperança, otimismo, admiração, confiança, medo e aflição.

\section{Avaliação da administração e do bem-estar econômico}

O eleitor avalia o governo considerando seu desempenho na área econômica (Fiorina, 1981). Caso o gestor seja candidato à reeleição, os eleitores olharão para trás e verificarão qual foi seu desempenho à frente do governo. Nesse caso, estamos diante do voto retrospectivo. No voto retrospectivo, o desempenho do gestor-candidato à frente da administração pública importa para o eleitor.

O bem-estar econômico do eleitor é o ingrediente principal do voto retrospectivo na eleição presidencial (Lavareda, 2009, p. 62). Se o eleitor estiver bem no âmbito econômico, ele optará por possibilitar que o gestor responsável por seu bem-estar continue a governar.

Na última disputa presidencial brasileira (2010), o bem-estar econômico contribuiu para o sucesso da candidatura de Dilma Rousseff. Pesquisa do IPMN realizada em Pernambuco revela que - inerente ao universo de eleitores que consideram que sua situação econômica melhorou muito nos últimos anos $(30,9 \%)$ - 66,3\% pretendiam votar na candidata do PT. ${ }^{21}$

Em agosto de 2010, segundo o Instituto de Pesquisa Datafolha, a candidata Dilma Rousseff era considerada por $49 \%$ dos eleitores brasileiros como a mais preparada para manter a estabilidade econômica e para 46\%, para lutar contra o desemprego. Seu principal oponente, José Serra, do Partido da Social Democracia Brasileira (PSDB), obteve, nos itens frisados, o percentual de $28 \%$.

Carreirão (2009, p. 45), ao desenvolver análise sobre as eleições de 2006, mostra que a avaliação da administração presidencial é intrinsecamente dependente do desempenho econômico do país. O autor afirma que Luiz Inácio Lula da Silva foi reeleito em razão da avaliação positiva da sua administração, que foi propiciada, dentre vários fatores, pelo bem-estar econômico.

Com base em survey realizado pelo IPMN e por meio do modelo de regressão logística, estimou-se a probabilidade de eleição do candidato à sucessão presidencial em 2010 no âmbito de Pernambuco. A variável dependente a ser estimada é (1) a intenção de voto no candidato da situação e (2) intenção de voto em outros candidatos. As variáveis explicativas são: avaliação da administração, preferência partidária e bem-estar econômico.

O modelo estimado mostra a probabilidade de o eleitor votar na candidata da situação, Dilma Rousseff. $\mathrm{O}$ efeito positivo mais forte para a formação da probabilidade da intenção de voto na candidata petista é oriundo da variável avaliação da administração, que é seguida pelo bem-estar econômico. A chance de um eleitor que considera a administração Lula ótima/boa votar em Dilma é 4,9 vezes maior do que o eleitor que não avalia bem a administração. A variável de menor efeito positivo é a preferência partidária.

20. Lavareda (2009; 2011) utiliza a neurociência para a construção dos seus argumentos, os quais são inovadores e interagem com as premissas do neoinstitucionalismo apresentadas neste artigo. Para uma abordagem da neurociência e a sua contribuição para a explicação do comportamento dos indivíduos, cf. Damásio (1996; 2011).

21. Pesquisa realizada em maio de 2010. O teste entre bem-estar econômico e intenção de voto apresentou p-valor < 0,05, indicando uma relação estatisticamente significativa entre as variáveis analisadas. 
Peixoto e Rennó (2011) apresentam argumento complementar e inovador quanto à relação bem-estar econômico e escolha eleitoral. Os autores mostram que a mobilidade social é a variável determinante que possibilitou o sucesso eleitoral de Dilma Rousseff na disputa presidencial de 2010. Peixoto e Rennó não desconsideram a variável bem-estar econômico, mas revelam que a percepção de mobilidade social ascendente por parte dos eleitores proporcionou que a candidata do PT conquistasse a Presidência da República.

Quando as eleições ocorrem nos âmbitos estadual e municipal, outros ingredientes surgem para qualificar a administração do gestor-candidato. Segundo Lavareda (2009, p. 61), os eleitores identificam as responsabilidades de cada esfera de governo - municipal, estadual e federal. Sendo assim, o desempenho dos gestores-candidatos à frente da saúde, da educação, da infraestrutura e da segurança pública são avaliados pelos eleitores nas eleições municipais e estaduais (Lavareda, 2009, p. 100).

Ao analisar diversas eleições municipais no Brasil, Almeida (2008) conclui que "pode-se dizer que os candidatos do governo tendem a vencer quando a soma de 'ótimo' e 'bom' está acima de 50\%” no tocante à avaliação da administração (Almeida, 2008, p. 36).

Oliveira e Santos (2009) concordam, em parte, com a tese de Almeida (2008), nas eleições municipais de 2008, porém, fazem ressalvas. O prefeito de Curitiba, Beto Richa (PSDB), foi candidato à reeleição e tinha, à época, 85\% de bom/ótimo. O prefeito do Recife, João Paulo, e o de Belo Horizonte, Fernando Pimentel, ambos do PT, tinham, à época, $64 \%$ e $75 \%$ de bom/ótimo respectivamente (Oliveira; Santos, 2009, p. 121).

João da Costa (PT), candidato apoiado por João Paulo, foi eleito no primeiro turno. Por sua vez, Márcio Lacerda (PSB), candidato apoiado por Fernando Pimentel, foi eleito no segundo turno (Oliveira; Santos, 2009, p. 120). Em razão de o prefeito de Belo Horizonte, Fernando Pimentel, não ter elegido seu candidato no primeiro turno, Oliveira e Santos (2009, p. 121) indagam: por que boas administrações nem sempre elegem candidatos no primeiro turno?

A indagação acima nos permite corroborar a conclusão de Oliveira e Santos (2009, p. 134): "Boas administrações" é uma variável que condiciona o sucesso eleitoral do candidato, mas não deve ser considerada como variável determinante. Outras características do candidato precisam sem consideradas, dentre estas, a imagem do candidato - variável sugerida por Carreirão (2002a).

Lavareda (2009, p. 49) afirma que a principal marca das eleições municipais de 2008 no Brasil foi a continuidade. "Foram eleitos em todo o país $67 \%$ dos prefeitos que se recandidataram. O índice alcançou $78 \%$ nos cem maiores municípios e chegou a 95\% nas capitais." Esses dados reforçam, inicialmente, a tese de Almeida (2008). Entretanto, Lavareda faz observações pertinentes.

Lavareda (2009) frisa que nem todos os prefeitos reeleitos em 2008 desfrutavam alta popularidade no início da campanha. Dos candidatos à reeleição nas capitais, 25\% não tinham “os 40\% de 'ótimo' ou 'bom' às vésperas do início oficial da campanha” (Lavareda, 2009, p. 49).

O bem-estar econômico dos eleitores propiciado pela administração federal; o aumento de recursos disponíveis para investimentos por parte dos prefeitos-candidatos; o controle da agenda da campanha; posição privilegiada para obter doações; condições propícias para formar alianças, e a propaganda eleitoral contribuem para o sucesso eleitoral dos candidatos à reeleição (Lavareda, 2009, p. 50).

As considerações de Lavareda (2009) reforçam a conclusão de Oliveira e Santos (2009) de que "boas administrações" é uma variável necessária, mas não suficiente para explicar o sucesso eleitoral do candidato. Além disso, os autores mostram que os prefeitos que não tinham à época do início da campanha eleitoral a aprovação condicional sugerida por Almeida (2008), ou seja, 50\% de bom/ótimo, conseguiram reeleger-se na disputa municipal de 2008.

Portanto, o percentual proposto por Almeida (2008), que dá sustentação empírica à tese de que boas administrações elegem candidatos, não deve ser determinista. Prefeitos com índices de aprovação menores do que 50\% também vencem a eleição. Nesse sentido, questionamos: por que "boas administrações" deve ser considerada uma variável condicional e não determinante para o sucesso eleitoral de dado candidato?

\section{A cultura política}

A cultura política representa os valores, o conjunto de atitudes e as crenças dos indivíduos - como eles olham e reconhecem o outro, os eventos sociais e as instituições (Porter, 2002; Hall; Taylor, 2003; Borba, 2005; Inglehart; Welzel, 2009; Fukuyama, 2010; Moisés, 2010).

Para especificamente o institucionalismo histórico e sociológico, os indivíduos adquirem cultura política durante seu percurso histórico, e neste interações sociais ocorrem com outros indivíduos. As interações sociais possibilitam a construção das visões de mundo dos indivíduos e orientam suas escolhas diante de uma lista de preferências (Boudon, 1995; Elster, 1997; Hall; Taylor, 2003). ${ }^{22}$ 
Diversos autores procuram mostrar empiricamente a importância de considerar a cultura política dos indivíduos na compreensão das suas escolhas. Eles corroboram Boudon (1995), porque reconhecem que os indivíduos não estão em um vazio social (Damatta, 1979; Landes, 2002; Borba, 2005; Almeida, 2007; Inglehart; Welzel, 2009; Souza; Lamounier, 2009).

As escolas sociológica e psicológica apresentadas por Figueiredo (1991), que buscam explicar teoricamente a escolha do eleitor, sugerem que compreender a cultura política dos eleitores possibilita a apreensão de como e por que os indivíduos adquirem ideologia, obtêm preferência partidária e constroem ou contraem valores que os incentivam a fazer suas escolhas eleitorais.

O eleitor poderá optar por um candidato caso sua cultura política e seus desejos correspondam à imagem ou às ideias apresentadas por ele. Como bem sugere Lourenço (2007), a imagem do candidato deve ser considerada um determinante do voto pelo fato de que os eleitores, a partir da sua cultura política, reconhecem positiva ou negativamente o candidato.

A imagem do candidato e a cultura política dos eleitores são formadas por atributos (Carreirão, 2002a). As diferenças de atributos na relação eleitorcandidato podem levar o indivíduo a não votar em certo competidor. As semelhanças/correspondências podem ter efeito contrário (Almeida, 2007; 2008; Lavareda, 2009; Oliveira; Gadelha; Santos, 2010).

Lavareda (2009, p. 73) argumenta que, com a compreensão das características do contexto da eleição e do que pensa o eleitor (cultura política), é possível definir estratégias de campanha para o candidato. São essas, de acordo com Lavareda (2009), que podem levar o candidato à conquista do poder.

As obras dos autores citados sugerem o seguinte problema: de que modo a cultura política dos indivíduos é adquirida e como esta influencia a escolha do eleitor?

\section{As campanhas e as estratégias eleitorais}

Os cientistas sociais desdenhavam das campanhas eleitorais (Lavareda, 2009, p. 133). ${ }^{23}$ Com a observação das campanhas eleitorais, é possível identificar as estratégias eleitorais. Estudá-las após o período eleitoral possibilita a compreensão, as razões que motivaram os eleitores a fazer suas escolhas.

Procurar entender as estratégias eleitorais dos candidatos significa que a competição eleitoral não finda antes do início da campanha eleitoral. O eleitor, durante a campanha eleitoral, em razão das estratégias dos candidatos, pode vir a mudar, construir ou consolidar a imagem que ele tem de dado concorrente (Lavareda, 2009, p. 133).

As estratégias eleitorais são determinantes do voto; por meio delas, o candidato pode vir a conquistar o eleitor. É importante entendê-las, pois o eleitor, na formação da sua preferência eleitoral, poderá sofrer influência não só de determinantes que influenciam ou são construídos no decorrer de uma longa trajetória, como preferência partidária, ideologia e cultura política, mas também dos que interferem na curta trajetória do eleitor, no caso, as estratégias de campanha (Lourenço, 2007; Telles, 2009).

As estratégias eleitorais podem vir a explorar a imagem dos candidatos, os feitos e as contribuições do governo para o eleitor. Elas divulgam apoios e associam imagens, associam temas a certo competidor com o objetivo de contrastar a cultura política de parte do eleitorado. As estratégias eleitorais possibilitam a interação eleitor-candidato e contribuem para a formação da escolha eleitoral (Lavareda, 2009; Telles, 2009).

Lourenço (2007) sugere que o eleitor constrói sua escolha durante a trajetória eleitoral, a qual tem início antes do guia eleitoral. A segunda etapa dessa trajetória ocorre com o início do guia, e a última etapa, na qual se dá a cristalização do voto, corresponde às duas últimas semanas finais da campanha (Lourenço, 2007, p. 126). Entretanto, consideramos que a trajetória eleitoral surge com o início do guia eleitoral. Antes dela, o eleitor está em sua trajetória histórica.

A propaganda eleitoral contribui para a massificação das estratégias eleitorais entre o eleitorado e para torná-las perceptíveis por parte dos analistas durante a trajetória eleitoral. Veiga (2001), Lourenço (2007) e Machado (2009) mostram de que modo as estratégias eleitorais são utilizadas no guia eleitoral e a importância delas para a formação da preferência eleitoral. Esses autores reconhecem o guia eleitoral como determinante do voto.

O guia eleitoral é um determinante do voto, mas também um instrumento que contribui para que os eleitores obtenham informações sobre os competidores e para que as estratégias de campanha adquiram poder/força de influência na formação da preferência do eleitor.

Em pesquisa do IPMN, de 27 e 28 de setembro de 2010, perguntou-se aos eleitores pernambucanos se eles assistiram à propaganda eleitoral dos candidatos ao governo do Estado nas eleições de 2010 ou a ouviram. Afirmaram que sim $42 \%$ dos eleitores e $55 \%$ frisaram que não. ${ }^{24}$ 
O Instituto Datafolha, na pesquisa de 13 a 15 de setembro de 2010, fez a seguinte pergunta aos eleitores brasileiros: "No último dia 17 , teve início o horário eleitoral gratuito na TV. Você assistiu algum dia pela TV à propaganda dos candidatos a presidente?" Responderam sim 51\% dos entrevistados. À pergunta do IPMN - o guia eleitoral influencia na escolha do seu candidato ao governo do estado de Pernambuco? -, de 27 a 28 de setembro de 2010, 24\% responderam que o guia influencia bastante. $\mathrm{O}$ mesmo percentual de eleitores considerou que influencia pouco, e $46 \%$ asseveraram que não influencia.

Os dados mostram, portanto, que o guia eleitoral é um instrumento que provoca a interação eleitorcandidato em específico espaço de tempo. Nessa interação, os determinantes do voto mostrados criam vida ou força e, por conseguinte, levam o guia eleitoral a ser reconhecido como mais um determinante do voto.

As obras que abordam as estratégias eleitorais e o papel do guia eleitoral provocam a elaboração do seguinte problema: é possível prognosticar resultados eleitorais antes do início do guia eleitoral? ${ }^{25}$

\section{A convergência entre as lacunas}

Os questionamentos apresentados no decorrer do texto evidenciam que existe convergência entre as lacunas teórica e empírica. Figueiredo (1991) procura responder teoricamente ao seguinte problema: o que motiva a ação social do eleitor? A resposta empírica a essa indagação se encontra, possivelmente, nos determinantes do voto apresentados pela literatura mostrada e pelas premissas dos institucionalismos histórico, sociológico e da teoria da escolha racional - neoinstitucionalismo.

A revisão das obras empíricas sugere que o eleitor não está no vazio social, como bem alerta Boudon (1995). Temos a hipótese de que os indivíduos formam suas preferências eleitorais, as quais podem ser racionais, no decorrer da sua trajetória - histórica e eleitoral. Em virtude disso, constatamos ser necessária a inserção do neoinstitucionalismo para a compreensão teórica e empírica da formação da preferência do eleitor e, por consequência, do entendimento do que motiva a escolha eleitoral dos indivíduos.

O neoinstitucionalismo procura decifrar as escolhas dos indivíduos considerando a trajetória percorri- da por eles e as interações sociais que nela ocorrerem. $\mathrm{Na}$ trajetória, os indivíduos adquirem cultura política em razão das interações sociais, e estas podem vir a limitar ou a construir o comportamento estratégico deles - path dependent. ${ }^{26}$ Além disso, instituições formais, como regras eleitorais, condicionam ou orientam as escolhas dos indivíduos (Hall; Taylor, 2003; Peters, 2003; Aoki, 2007; Rezende, 2009, 2012).

O eleitor sabe atribuir características/atributos aos espectros ideológicos e, por consequência, às agremiações partidárias? Singer $(2000$, p. 143) afirma que a identificação do eleitor com a esquerda e a direita parte de um conhecimento intuitivo, "de um sentimento do que significam as posições ideológicas. Esse sentimento permite ao eleitor colocar-se na escala em uma posição que está de acordo com suas inclinações, embora não saiba verbalizar". Segundo Singer (2000, p. 143), o desafio é descobrir a visão de mundo "que está associada a essa identificação intuitiva”.

Singer (2000) reconhece que é necessária a compreensão da visão de mundo dos indivíduos para a compreensão das suas escolhas. Para tal empreitada, portanto, o neoinstitucionalismo contribui, pois ele considera que os indivíduos interagem com outros indivíduos e adquirem visões de mundo/cultura política (Hall; Taylor, 2003; Peters, 2003; Aoki, 2007). ${ }^{27}$

De que modo a imagem do candidato é construída, aceita ou rejeitada pelo eleitor? A hipótese é que os indivíduos realizam suas escolhas baseadas em expectativas do que poderá vir a ocorrer diante de determinada ação (Aoki, 2007, p. 2). Desse modo, a expectativa do eleitor pode estar associada à imagem que ele tem dos competidores no processo eleitoral.

Diante da circunstância política caracterizada por intensas denúncias de corrupção advindas da imprensa, envolvendo variados atores políticos, por exemplo, o eleitor pode ter o desejo de votar em um candidato que tenha atributos pessoais que vão de encontro à circunstância atual. Ele, então, opta por votar em candidatos que apresentem como atributos pessoais a honestidade, já que ele tem a expectativa de que se, esse competidor for o vencedor, ele exercerá seu mandato com honestidade.

Carreirão (2002a) afirma que os atributos pessoais dos candidatos interferem na escolha do eleitor. Os atributos do candidato constroem e integram sua imagem. O candidato pode apresentar-se ao eleitor com a imagem moldada pelo marketing em razão das exigências e expectativas do eleitor (Figueiredo, 2008).

25. Prognosticar situações ou resultados eleitorais significa construir cenários; e, ainda, reduzir as possibilidades de que algum evento ocorra. Sobre prognósticos eleitorais, cf. Armstrong (2000).

26. A path dependente parte do princípio de que a ação do indivíduo ou as causalidades sociais dependem da trajetória percorrida. Nesse caso, a ação social do indivíduo ou das instituições pode ser motivada pela acumulação de causas ocorridas nas várias etapas da trajetória (Pierson, 2000).

27. Diante dessa parcial conclusão, um problema surge: os partidos políticos no Brasil têm diferenças ideológicas? 
Porém, o eleitor construiu suas expectativas não só em razão de dada circunstância política, mas também por conta de que, no decorrer da sua trajetória, ele adquiriu valores, tais como o de exigir que políticos exerçam o mandato público com honestidade. Além disso, regras eleitorais podem orientar ou limitar as escolhas do eleitor.

Que premissa teórica fundamenta a imagem como determinante do voto? $\mathrm{O}$ neoinstitucionalismo tem condições de explicar teoricamente a utilização da imagem como determinante do voto, pois o eleitor, no decorrer da sua trajetória, adquire cultura política que contribui para a formação das suas preferências e expectativas eleitorais. As expectativas, por sua vez, orientam-no na escolha do seu candidato, a qual se pauta na correspondência de valores entre eleitor-candidato.

$\mathrm{Na}$ trajetória, que pode ser a eleitoral, ocorre a interação de eleitores com candidatos. Nessa trajetória surgem ou são incentivados os sentimentos do eleitor para com o candidato. O desempenho do gestor-candidato no governo ou do candidato na campanha eleitoral pode despertar emoções no eleitor. Portanto, a relação emocional/sentimental entre eleitor-candidato é construída numa trajetória.

A avaliação positiva das administrações contribui para o sucesso eleitoral do gestor-candidato. Entretanto, o eleitor está numa trajetória em que nela estão presentes estágios. Nos estágios iniciais, antes da sua definitiva decisão eleitoral, o eleitor pode ter escolhido, em razão da avaliação da administração positiva do gestor-candidato $\mathrm{X}$, votar por sua reeleição.

Diante do início do guia eleitoral, pode ocorrer que o eleitor perceba que o candidato $X$ não merece seu voto e opta por votar no candidato Y. Sendo assim, o eleitor, em razão de estar numa trajetória e nesta receber influências diversas, inclusive do guia eleitoral (instituição), pode modificar sua opinião.

Desse modo, a variável "Boa administração" não deve ser reconhecida como determinante, mas sim condicional, já que ela pode ser desconstruída durante a trajetória eleitoral. Em razão disso, gestorescandidatos ou candidatos apoiados por gestores bem avaliados podem vir a vencer a disputa eleitoral apenas no segundo turno, por exemplo.

Veiga (2001) e Lavareda (2009) mostram o impacto do guia eleitoral e das estratégias eleitorais sobre o eleitor. Ao incorporar a premissa tão defendida neste trabalho de que os eleitores formam sua preferência eleitoral numa trajetória, constatamos que talvez seja impossível prever resultados eleitorais antes do guia eleitoral, uma vez que ele pode modificar as escolhas dos eleitores.

\section{Conclusão}

O neoinstitucionalismo contribui para a compreensão das escolhas dos eleitores em razão de sugerir que elas se constroem numa trajetória. Portanto, os indivíduos constroem suas escolhas; elas não surgem do nada. As variadas obras abordadas neste trabalho explicam o comportamento do eleitor, e muitas delas fazem isso de modo inovador, no caso, sugerindo outros determinantes. Entretanto, elas não recomendam de modo nítido que a preferência eleitoral seja construída numa trajetória. Em razão disso, conforme mostrado, indagações teóricas e empíricas ficam sem respostas.

Vários candidatos são oferecidos para o eleitor na trajetória eleitoral. Os diversos determinantes do voto que foram apresentados podem influenciar conjuntamente ou não a escolha do eleitor. O eleitor, portanto, toma sua decisão em razão de variáveis causais ou condicionais que constroem suas escolhas nas trajetórias. ${ }^{28}$ A escolha do eleitor não é estática. Ela - conforme os contextos/estágios, os quais surgem durante a trajetória - pode ser modificada.

O neoinstitucionalismo, aqui reconhecido como a união das premissas advindas dos diversos institucionalismos (histórico, escolha racional e sociológico), mostra que as preferências dos indivíduos, além das suas escolhas, constroem-se historicamente em razão das interações sociais e da influência das instituições. As escolhas podem ser racionais. Contudo, para o neoinstitucionalismo, a escolha racional é variante e contextual.

Este artigo mostra que é simplista afirmar que os eleitores fazem simplesmente escolhas racionais. Tal assertiva desconsidera que os indivíduos estão numa trajetória construindo suas escolhas, as quais, é bom repetir, sofrem influências diversas. Ela também possibilita o enfraquecimento dos seguintes determinantes do voto: cultura política, ideologia, emoções, sentimentos e imagem. Esses determinantes importam na explicação do comportamento do eleitor.

Assim, os variados determinantes do voto apresentados têm relevância. As obras aqui abordadas mostram a viabilidade empírica de considerá-los na explicação da escolha do eleitor, mas, para tanto, é necessário utilizar as premissas teóricas do neoinstitucionalismo, porque elas estruturam teoricamente os determinantes do voto.

Além disso, a escolha racional, quando utilizada de modo solitário, não dá conta de mostrar a relevância explicativa desses determinantes em sua totalidade, mas de alguns. Em razão disso, propomos que a

28. O candidato $X$ foi reeleito (variável dependente) em razão de sua administração ser aprovada por 65\% dos eleitores (variável independente). Estes afirmam que o principal mérito do gestor $X$ foi propiciar o crescimento econômico (variável condicional). Portanto, o crescimento econômico condicionou a alta aprovação do competidor X. 
agenda de pesquisa no âmbito dos estudos eleitorais incorpore o neoinstitucionalismo na explicação das escolhas do eleitor.

\section{Referências}

ALMEIDA, Alberto Carlos. A cabeça do brasileiro. São Paulo: Record, 2007. . A cabeça do eleitor. São Paulo: Record, 2008.

AOKI, Masahiko. Endogenizing institutions and institutional changes. Journal of Institutional Economics, v. 3, $\mathrm{n}^{\circ}$ 1, p. 1-31, 2007.

ARMSTRONG, J. Scott (Ed). Principles of forecasting: a handbook for researchers and practitioners. Norwell, MA: Kluwer Academic Publishers, 2000.

BORBA, Julian. Cultura política, ideologia e comportamento eleitoral: alguns apontamentos teóricos sobre o caso brasileiro. Opinião Pública, v. 11, n 1, p. 147168, mar. 2005

BOUDON, Raymond (Org.). Tratado de sociologia. Tradução de Teresa Curvelo. Rio de Janeiro: Jorge Zahar, 1995.

CARPENTER, Daniel. Where do the premises of political choice come from?: In: KING, Gary; SCHLOZMAN, Kay L.; NIE, Norman (Ed.). The future political science: 100 perspectives. New York and London: Routledge, 2009.

CARREIRÃO, Yan de Souza. A decisão do voto nas eleições presidenciais brasileiras. Rio de Janeiro: Fundação Getúlio Vargas, 2002a.

. Identificação ideológica e voto para presidente. Opinião Pública, v. 8, n 1 , nov. 2002 b.

Identificação ideológica, partidos e voto na eleição presidencial de 2006. Opinião Pública, v. 13, n 2, nov. 2007.

La elección presidencial brasileña de 2006: voto econômico e clivajes sociales. In: BRAUN, Maria; STRAW, Cecília (Org.). Opinion Pública: una mirada desde América Latina. Buenos Aires: Planeta, 2009.

Opiniões políticas e sentimentos partidários dos eleitores brasileiros. Opinião Pública, v. 14, nº 2, nov. 2008. ; BARBETTA, Pedro Alberto. A eleição presidencial de 2002: a decisão do voto na região da Grande São Paulo. Revista Brasileira de Ciências Sociais, v. 19, no 56, out. 2004

DAMÁSIO, António R. E o cérebro criou o homem. São Paulo: Companhia das Letras, 2011.

O erro de Descartes: emoção, razão e cérebro humano. São Paulo: Companhia das Letras, 1996.

DAMATTA, Roberto da. Carnavais, malandros e heróis. Rio de Janeiro: Rocco, 1979.

DOWNS, Anthony. Uma teoria econômica da democracia. São Paulo: Edusp, 1999.

ELSTER, Jon. El cambio tecnológico: investigaciones sobre la racionalidad y la transformación social. Traducción
Margarita Mizraji. 5. ed. Barcelona: Gedisa, 2006. Egonomics: análisis de la interacción entre racionalidad, emoción preferencias y normas sociales en la economia de la acción individual y sus desviaciones. Traducción Irene Cudich. Barcelona: Gedisa, 1997. FIGUEIREDO, Marcus. A decisão do voto. São Paulo: Sumaré; Anpocs, 1991.

FIGUEIREDO, Rubens (Org.). Marketing político em tempos modernos. Rio de Janeiro: Fundação Konrad Adenauer, 2008.

FIORINA, Morris. Retrospective voting in American national elections. New Haven; London: Yale University, 1981.

FUKUYAMA, Francis. Ficando para trás. Tradução de Nivaldo Montingelli Jr. Rio de Janeiro: Rocco, 2010.

HALL, Peter A.; TAYLOR, Rosemary C. R. As três versões do neoinstitucionalismo. Revista Lua Nova, $\mathrm{n}^{\circ} 58$, p. 193-223, 2003.

INGLEHART, Ronald; WELZEL, Christian. Modernização, mudança cultural e democracia. São Paulo: Francis \& Verbena, 2009.

LANDES, David. Quase toda a diferença está na cultura. In: HARRISON, L. E.; HUNTINGTON, S. P. (Org.). A cultura importa. Tradução de Berilo Vargas. Rio de Janeiro: Record, 2002.

LAVAREDA, Antonio. Emoções ocultas e estratégias eleitorais. Rio de Janeiro: Objetiva, 2009.

Neuropolítica: o papel das emoções e do inconsciente. Dossiê Marketing Político, no 90, p. 120-146, jun./ago. 2011.

LIMONGI, Fernando; MESQUITA, Lara. Estratégia partidária e preferência dos eleitores: as eleições municipais em São Paulo entre 1985 e 2004. Novos estudos Cebrap, no 81, p. 49-67, 2008. Disponível em: <http://dx.doi.org/10.1590/ S0101-33002008000200006>. Acesso em: 19 fev. 2012.

LOURENÇO, Luiz Cláudio. Abrindo a caixa-preta: da indecisão à escolha a eleição presidencial de 2002. Rio de Janeiro, 2007. Tese (Doutorado em Ciências Políticas e Sociologia) - Instituto Universitário de Pesquisas do Rio de Janeiro.

MACHADO, Mônica. A retórica da reeleição: mapeando os discursos dos programas eleitorais (HGPE) em 1998 e 2006. Opinião Pública [on-line], v. 15, nº 1, p. 159-189, 2009. Disponível em: <http://dx.doi.org/10.1590/S010462762009000100007>. Acesso em: 19 fev. 2012.

MARCUS, G. The psychology of emotions and politics. In: SEARS, D.; HUDDY, L.; JERVIS, R. (Org.) Oxford handbook of political psychology. Oxford: Oxford University Press, 2003. 
MOISÉS, José Álvaro (Org.). Democracia e confiança: por que os cidadãos desconfiam das instituições públicas? São Paulo: Edusp, 2010.

OLIVEIRA, Adriano. O lulismo e as suas manifestações no eleitorado. Revista Debates, v. 5, no 1, p. 115-138, jul.dez. 2011.

; GADELHA, Carlos; SANTOS, Roberto. O que pensa o eleitor pernambucano?: análise, comunicação política e instituições. Recife: Bagaço, 2010.

OLIVEIRA, Adriano; SANTOS, Roberto. Boas administrações elegem candidatos?: análise do comportamento dos eleitores em sete capitais brasileiras nas eleições de 2008. Revista Debates, v. 3, nº 2, p. 116-138, jul./dez. 2009.

PEIXOTO, Vitor; RENNÓ, Lúcio. Mobilidade social ascendente e voto: as eleições presidenciais de 2010 no Brasil. Opinião Pública, v. 17, n 2, nov. 2011. Disponível em: <http://dx.doi.org/10.1590/S010462762011000200002>. Acesso em: 6 fev. 2012.

PETERS, B. Guy. El nuevo institucionalismo: teoria institucional em ciencia política. Tradução Verônica Tirotta. Barcelona: Gedisa, 2003.

PIERSON, Paul. Increasing returns, path dependence, and the study of politics. American Political Science Review, v. $94, n^{\circ} 2$, June 2000.

PIMENTEL JÚNIOR, Jairo Tadeu Pires. Razão e emoção: o voto na eleição presidencial de 2006. São Paulo, 2007. Dissertação (Mestrado em Ciências Sociais) - Programa de Pós-Graduação em Ciência Política, Departamento de Ciência Política, Faculdade de Filosofia, Letras e Ciências Humanas, Universidade de São Paulo.

Razão e emoção: o voto na eleição presidencial de 2006. Opinião Pública, v. 16, nº 2, p. 516-541, nov. 2010. POPPER, Karl. Lógica das ciências sociais. Tradução de Estevão de Rezende Martins, Apio Claudio Muniz Acquarone Filho, Vilma de Oliveira Moraes e Silva. 3. ed. Rio de Janeiro: Tempo Brasileiro, 2004.

PORTER, Michael Eugene. Atitudes, valores, crenças e a microeconomia. In: HARRISON, Lawrence E.; HUNTINGTON, Samuel P. (Org.). A cultura importa.
Tradução de Berilo Vargas. Rio de Janeiro: Record, 2002. PRZEWORSKI, Adam. . A última instância: as instituições são a causa primordial do desenvolvimento econômico. Novos Estudos Cebrap, no 72, p. 59-77, 2005. REIS, Fábio Wanderley. Mercado e utopia: teoria política e sociedade brasileira. São Paulo: Ed. da Universidade de São Paulo, 2000.

REZENDE, Flávio. Analytical challenges for neoinstitucional theories of institucional change in comparative political science. Brazilian Political Science Review, v. 3, n 2, p. 98-126, 2009.

Convergências e controvérsias sobre a mudança institucional: modelos tradicionais em perspectiva comparada. Revista de Sociologia Política, v. 20, n 41, p. 3751, fev. 2012.

SINGER, André. Esquerda e direita no eleitorado brasileiro: a identificação ideológica nas disputas presidenciais de 1989 e 1994. São Paulo: Edusp, 2000.

. As raízes sociais e ideológicas do lulismo. Novos Estudos, no 85, p. 82-103, dez. 2009. Disponível em: <http:// novosestudos.uol.com.br/acervo/acervo_artigoasp? idMateria $=1356>$. Acesso em: 14 fev. 2010 .

SOUZA, Amaury de; LAMOUNIER, Bolívar. A classe média brasileira: ambições, valores e projetos de sociedade. Rio de Janeiro: Campus-Elsevier, 2009.

TALEB, Nassim Nicholas. A lógica do cisne negro: o impacto do altamente improvável. Tradução de Marcelo Schild. 3. ed. Rio de Janeiro: BestSeller, 2009.

TELLES, Helcimara de Souza. Estrategias de campaña política: esloganes y retóricas en eleccionnes para alcade en Brasil. América Latina Hoy, v. 51, p. 141-168, 2009.

VAN EVERA, Stephen. Guide to methods for students of political science. New York: Cornell University, 1997.

VEIGA, Luciana Fernandes. Em busca de razões para o voto: o uso que o homem comum faz do horário eleitoral. Tese (Doutorado em Ciência Política) - Instituto Universitário de Pesquisas do Rio de Janeiro, Rio de Janeiro, 2001.

WESTEN, Drew. The political brain: the role of emotion in deciding the fate of the nation. New York: Public Affairs/ Perseus Books, 2007. 


\title{
State of the art of vote determinants in Brazil and existing gaps
}

\begin{abstract}
By reviewing vote determinants presented by the Brazilian literature and through the presentation of neo-institutionalism basic premises, this article aims to: show various authors' contributions concerning voter's choice explanations; highlight research gaps existing on the scope of works that address vote determinants; and justify the necessity of using the neo- institutionalism in the interpretation of voter's behavior. We concluded that for a sounding theoretical and empirical understanding of voter's choice it is required to use the neo- institutionalism in interpreting vote determinants influence.
\end{abstract}

Key words: voting behavior, vote determinants, elections, choice, neo-institutionalism.

\section{El estado de la cuestión de los determinantes del voto en Brasil Y las lagunas}

\section{Resumen}

A través de la revisión de los determinantes de voto presentada por la literatura brasileña y la presentación de las premisas básicas del neo-institucionalismo, este artículo tiene como objetivo mostrar las contribuciones de diversos autores como consistentes con las explicaciones de las opciones del votante, las diferencias de relieve en la investigación dentro de las obras existentes que aborden los determinantes de los votos, justificar la necesidad de uso de lo neo-institucionalismo en la interpretación de la conducta de los votantes. Llegamos a la conclusión de que para la comprensión teórica y empírica robusta de la elección del votante, es necesario el uso de neo-institucionalismo en la interpretación de la influencia de los factores determinantes de los votos.

Palabras-clave: el comportamiento electoral, determinantes de los votos, las elecciones, elección, neo-institucionalismo.

Data de recebimento do artigo: 07/09/2011

Data de aprovação do artigo: 17/03/2012 